\title{
Kawasaki Disease with Mild Encephalitis/Encephalopathy with Reversible Splenial Lesion in a 2-Year-Old Girl
}

\author{
Shinya Yoshihara ${ }^{1} \cdot$ Yuji Fujita $^{1}$ (D) $\cdot$ Kenji Miyamoto $^{1} \cdot$ George Imataka $^{1} \cdot$ Shigemi Yoshihara $^{1}$
}

Received: 11 January 2021 / Accepted: 15 April 2021 / Published online: 3 May 2021

(C) Dr. K C Chaudhuri Foundation 2021

To the Editor: Mild encephalitis/encephalopathy with a reversible splenial lesion (MERS) is a common acute encephalopathy in Japan [1]. It is usually caused by viruses such as influenza; however, it has recently been associated with Kawasaki disease (KD) [2].

A 2-y-old girl was diagnosed with KD on day 4. Blood examination revealed white blood cells (WBC) $8600 / \mu \mathrm{L}$ (neutrophils: $80.4 \%$ ), platelets $275,000 / \mu \mathrm{L}$, aspartate aminotransferase (AST) $80 \mathrm{IU} / \mathrm{L}$, sodium $131 \mathrm{mmol} / \mathrm{L}, \mathrm{C}$-reactive protein (CRP) $9.28 \mathrm{mg} / \mathrm{dL}$. On day 4, intravenous immunoglobulin (IVIG; $2 \mathrm{~g} / \mathrm{kg} / \mathrm{d}$ ) and aspirin were administered. On the same night, she started speaking incoherently and had altered consciousness. On day 5, MERS was diagnosed based of brain magnetic resonance imaging (MRI) findings. Methylprednisolone $(30 \mathrm{mg} / \mathrm{kg} /$ d) was administered for $3 \mathrm{~d}$. She was afebrile on day 6 , and her neurological symptoms improved on day 8 . She was discharged on day 13 without coronary artery lesions (CALs) or neurological sequelae.

Serum (day 4, pre-IVIG) and cerebrospinal fluid (day 5, post-IVIG) concentrations of interleukin (IL)-6, IL-18, and tumor necrosis factor (TNF)- $\alpha$ were measured. Serum cytokines on day 4 showed IL-6, IL-18, and TNF- $\alpha$ levels of $154 \mathrm{pg} / \mathrm{mL}, 615 \mathrm{pg} / \mathrm{mL}$, and $14.9 \mathrm{pg} / \mathrm{mL}$, respectively. CSF cytokines on day 5 showed IL-6, IL-18, and TNF- $\alpha$ levels of $6.04 \mathrm{pg} / \mathrm{mL},<78 \mathrm{pg} / \mathrm{mL}$, and $<2.24 \mathrm{pg} / \mathrm{mL}$, respectively.

In recent years, a high level of IL-6 has been reported as a risk factor for CALs [3]. A previous study reported that the mean pre-IVIG IL-6 levels in patients of KD with CALs were about three times higher than that in patients of $\mathrm{KD}$ without CALs (143.60 pg/mL vs. $52.90 \mathrm{pg} / \mathrm{mL}$ ). Several studies have also reported that IL-6 in the CSF might be associated with MERS [4].

It could be considered that KD complicated with MERS has a higher risk of CALs. Further research on the pathogenesis and appropriate treatment of KD with MERS is required.

\section{Declarations}

Conflict of Interest None.

\section{References}

1. Mizuguchi M, Ichiyama T, Imataka G, et al. Guidelines for the diagnosis and treatment of acute encephalopathy in childhood. Brain and Development. 2021;43:2-31.

2. Takanashi J, Shirai K, Sugawara Y, Okamoto Y, Obonai T, Terada H. Kawasaki disease complicated by mild encephalopathy with a reversible splenial lesion (MERS). J Neurol Sci. 2012;315:167-9.

3. Nandi A, Pal P, Basu S. A comparison of serum IL6 and CRP levels with respect to coronary changes and treatment response in Kawasaki disease patients: a prospective study. Rheumatol Int. 2019;39:1797-801.

4. Miyata R, Tanuma N, Hayashi M, et al. Oxidative stress in patients with clinically mild encephalitis/encephalopathy with a reversible splenial lesion (MERS). Brain Dev. 2012;34:124-7.

Publisher's Note Springer Nature remains neutral with regard to jurisdictional claims in published maps and institutional affiliations.

Yuji Fujita

fujitay@ dokkyomed.ac.jp

1 Department of Pediatrics, Dokkyo Medical University, 880 Kitakobayashi, Mibu, Shimotsuga, Tochigi 321-0293, Japan 